\title{
Genetic characterisation of Giardia duodenalis in dairy cattle in Brazil
}

\author{
Flávio Medeiros Paz e Silva², Raimundo Souza Lopes ${ }^{1}$ and João Pessoa Araújo Jr. ${ }^{2}$
}

\author{
${ }^{1}$ Laboratory of Parasitic Diseases, Department of Veterinary Clinic, Faculty of Veterinary Medicine and Animal Science, \\ UNESP - Univ. Estadual Paulista, Botucatu, São Paulo, Brazil; \\ ${ }^{2}$ Laboratory of Molecular Diagnosis, Department of Microbiology and Immunology, Bioscience Institute, UNESP - Univ. \\ Estadual Paulista, Botucatu, São Paulo, Brazil
}

\begin{abstract}
The intestinal protozoan parasite Giardia duodenalis (Lambl, 1859) Kofoid \& Christiansen, 1915 [syn. Giardia intestinalis and Giardia lamblia] has emerged as a widespread enteric pathogen in humans and domestic animals. In recent years, G. duodenalis has been found in cattle worldwide and longitudinal studies have reported cumulative prevalence of $100 \%$ in some herds. In the present study, we determined the prevalence and genetic characterisation of G. duodenalis in 200 dairy cattle from 10 dairy farms in São Paulo state, Brazil. All faecal specimens were screened for the presence of $G$. duodenalis using microscopy examination, enzyme immunoassay (EIA) and polymerase chain reaction (PCR). DNA was extracted from faecal samples and G. duodenalis were identified by amplification of the small subunit ribosomal (SSU-rDNA) and glutamate dehydrogenase (GDH) genes followed by restriction fragment length polymorphism (RFLP) or sequencing analysis. Giardia was identified in eight farm locations (80\% prevalence). Overall, 15/200 (7.5\%) animals were positive for infection, only one of which was a cow. Giardia duodenalis genotype E was present in 14 of the animals tested. Zoonotic genotype AI was present in one positive sample. Genotype E and genotype A represented $93 \%$ and $7 \%$ of $G$. duodenalis infections, respectively. This study demonstrates that $G$. duodenalis infection was prevalent in dairy calves in São Paulo state and that the non-zoonotic genotype E predominates in cattle in this region. Nevertheless, calves naturally infected in Brazil can shed Giardia cysts that can potentially infect humans, and thus, they may represent a public health risk.
\end{abstract}

Keywords: Giardia duodenalis, cattle, PCR-RFLP, sequencing, genotyping

Giardia duodenalis (Lambl, 1859) Kofoid \& Christiansen, 1915 [syn. Giardia intestinalis and Giardia lamblia] is an intestinal parasite commonly identified in mammals, including humans. The protozoan is prevalent in many parts of the world and is commonly isolated in the faeces of calves (Becher et al. 2004, Trout et al. 2005). This microorganism has been found in beef and dairy cattle worldwide (Appelbee et al. 2003, Barwick et al. 2003). Prevalence rates can vary, but this variation reflects differences in management, climate and study design (Olson et al. 1997, 2004). Studies reported that these parasites were highly prevalent in calves with infection rates as high as $100 \%$ in some herds (O'Handley et al. 1999, Ralston et al. 2003). An association was demonstrated between parasite infection, resultant diarrhoea and significant production losses (Olson et al. 1995, O'Handley et al. 2000, Huetink et al. 2001).

Taxonomy of the genus is mainly based on morphology and genetic profiles (Thompson et al. 2000). According to these criteria, six Giardia species have been recognized: G. agilis in amphibians, G. muris and G. microti in rodents, G. psittaci and G. ardeae in birds and G. duodenalis in mammals (Thompson 2004). Giardia duodenalis is the only species found in both humans and other mammals, including domestic and farm animals such as dogs, cats, cattle, pigs, sheep and horses (Thompson 2000, Hunter and Thompson 2005).

Molecular genetic studies have demonstrated that G. duodenalis is a complex species comprising at least seven major genotypes (Monis et al. 2003). Genotypes A and B appear to have the widest host ranges, including humans, cattle, other domesticated animals and wild animal species; genotypes $\mathrm{C}$ and $\mathrm{D}$ infect dogs, genotype E infects hoofed livestock, genotype F infects cats, and genotype G infects rats (Thompson 2000, Monis and Thompson 2003). Genotype A consists of isolates that can be grouped into two distinct clusters; AI consists of a mixture of closely related animal and human isolates which are geographically widespread, and most attention regarding the zoonotic potential of Giardia has focused on the AI subgroup (Olson et al. 2004, Thompson 2004). In contrast, the second subgroup, AII consists entirely of 
human isolates. Genotype B comprises two subgroups, III and IV, and the latter appears to be human-specific (Monis et al. 2003, Read et al. 2004).

Genotype $\mathrm{E}$ is the predominant genotype found in beef and dairy cattle in Australia, Canada, the United States and the Netherlands (O'Handley et al. 2000, Huetink et al. 2001, Appelbee et al. 2003, Trout et al. 2006) but a small percentage of genotype A has been found in these same studies. Despite the abundance of $G$. duodenalis around the world, there is little information on the genotypes in infected cattle in Brazil. This study was undertaken to determine the occurrence and genetic variants of $G$. duodenalis in dairy cattle in south-central São Paulo state, Brazil.

\section{MATERIALS AND METHODS}

\section{Dairy farms and sample collection}

Faeces were collected from dairy cattle located on 10 dairy farms in three counties (Pardinho, Botucatu and Itatinga) of south-central São Paulo state, Brazil (Table 1). All farms were visited between February and August 2006. Dairy calves and cows were randomly selected for sampling in accordance with the availability of animals on the properties. At each farm, 20 faecal specimens were collected from calves (2 weeks to 6 months of age) and cows ( $>24$ months). Two hundred cattle faecal samples were collected in total (100 from calves and 100 from cows). Faeces were collected directly from the rectum of each animal with a gloved hand and transferred into a plastic cup. Animals were generally grazed on pasture, housed in groups in large pens (either completely or partially covered by a roof) or housed in large free-stall barns.

\section{Light microscopy examination}

Zinc sulfate flotation (Faust et al. 1938) was employed to detect the presence of Giardia cysts in the faeces. Approximately 1-2 gram of each fresh faeces was mixed with distilled water, vortexed thoroughly and filtered into a disposable plastic tube ( $15 \mathrm{ml}$ in volume). The filtrate was centrifuged at $1,500 \mathrm{~g}$ for $3 \mathrm{~min}$ and the supernatant was discarded. The pellet was resuspended in distilled water to final volume of $15 \mathrm{ml}$ and centrifuged at 1,500 $\mathrm{g}$ for $1 \mathrm{~min}$. After this wash step, the supernatant was discarded and $\mathrm{ZnSO}_{4}$ solution with a specific gravity of 1.2 was added to the sediment, mixed thoroughly and centrifuged at $1,500 \mathrm{~g}$ for $1 \mathrm{~min}$. Zinc sulfate solution was added up to the rim of the tube and a cover glass (size: $18 \mathrm{~mm} \times 18 \mathrm{~mm}$ ) was put on top of the tube. After $3 \mathrm{~min}$, the cover glass was removed from the tube, placed on a microscope slide and stained with iodine. The preparations were examined under $\times 100$ magnification for 5 min for the presence of cysts. The identity of parasitic stages was confirmed by examining them under $\times 400$ magnification. Animals were considered positive if a $G$. duodenalis cyst with the correct morphology (12-14 $\mu \mathrm{m}$ in length with an axostyle and two or four nuclei) was detected in the sample.

\section{Antigen-EIA}

The GIARDIA II® antigen EIA (Techlab, USA) was used to identify the presence of cysts in $10 \%$ formalin preserved samples. The diagnostic kit procedure was followed. The results were examined and interpreted according to the manufacturer's instructions. One hundred microlitres of a $10 \%$ formalin-preserved stool sample were used for the assay. Bound antigen
Table1. City, farm designation, number of samples examined at each farm, number of positives, and prevalence rates of G. duodenalis genotypes from 200 dairy animals on 10 farms in southcentral São Paulo state, Brazil.

\begin{tabular}{llcccc}
\hline \multirow{2}{*}{ City } & \multirow{2}{*}{ Farm } & \multirow{2}{*}{$\begin{array}{c}\text { No. of } \\
\text { samples }\end{array}$} & \multirow{2}{*}{$\begin{array}{c}\text { No. of } \\
\text { positives }\end{array}$} & \multicolumn{2}{c}{ Genotype } \\
\cline { 5 - 6 } & & & $1(5)$ & $1(100)$ & 0 \\
Pardinho & PAR 1 & 20 & $4(20)$ & $3(75)$ & $1(25)$ \\
Pardinho & PAR 2 & 20 & $3(15)$ & $3(100)$ & 0 \\
Botucatu & BTU 1 & 20 & 0 & 0 & 0 \\
Botucatu & BTU 2 & 20 & 0 & 0 & 0 \\
Botucatu & BTU 3 & 20 & $2(10)$ & $2(100)$ & 0 \\
Botucatu & BTU 4 & 20 & $1(5)$ & $1(100)$ & 0 \\
Botucatu & BTU 5 & 20 & $2(10)$ & $2(100)$ & 0 \\
Itatinga & ITA 8 & 20 & $1(5)$ & $1(100)$ & 0 \\
Itatinga & ITA 9 & 20 & $1(5)$ & $1(100)$ & 0 \\
Itatinga & ITA 10 & 20 & $15(7.5)$ & $14(93.33)$ & $1(6.66)$ \\
\hline Total & 10 & 200 & &
\end{tabular}

was detected by a horseradish peroxidase-conjugated secondary monoclonal antibody and tetramethylbenzidine substrate. Results were read photometrically at $450 \mathrm{~nm}$. A sample was considered positive when O.D. was $>0.150$ at $450 \mathrm{~nm}$.

\section{Isolation of DNA}

DNA was extracted directly from $200 \mathrm{mg}$ of each faecal sample using the QIAmp DNA Stool Mini Kit (Qiagen, Germany) following the manufacturer's recommended protocol with slight modifications. Briefly, the samples were boiled for $5 \mathrm{~min}$, exposed to four cycles of freezing in liquid nitrogen for $5 \mathrm{~min}$ and then boiled for an additional 5 min. Cycling between freezing and boiling temperature served to disrupt the cell walls of the cysts and to release the DNA. Elution of the DNA was performed with $100 \mu$ lof elution solution to increase the quantity of recovered DNA. DNA was stored at $-20^{\circ} \mathrm{C}$ until it was used in the PCR assays.

\section{PCR analysis}

Faecal specimens frequently contain PCR inhibitors and a large number of cells from the host (e.g., intestinal and blood cells). The adequacy of DNA isolation and purification was assessed for each isolate by first performing PCR amplification with specific primer sets targeting the mitochondrial DNA from bovine cells, as previously described (Martelinni et al. 2005). Mitochondrial DNA gene targets were chosen for this assay because individual host cells contain numerous copies of mitochondrial DNA. The successful amplification of this target demonstrates the absence of inhibitors in a DNA sample originating from faeces.

\section{Polymerase chain reaction}

A 292-bp region of the small subunit ribosomal gene (SSUrDNA) was amplified by PCR as previously described (Hopkins et al. 1997, Leonhard et al. 2007). Each specimen was analyzed at least twice by PCR.

\section{GDH semi-nested PCR}

A fragment of the GDH gene for Giardia (432 bp) was amplified by a semi-nested PCR using primers GDHeF, GDHiR and GDHiF as previously described (Read et al. 2004) with some modifications. PCRs reactions were performed in a total volume of $25 \mu$ l, with the primary PCR reaction mixture containing $12.5 \mu 12 \times$ GoTaq $^{\circledR}$ (Promega, USA) Green Master Mix buffer (pH 8.5, $400 \mu \mathrm{M}$ dATP, $400 \mu \mathrm{M}$ dGTP, $400 \mu \mathrm{M}$ dCTP, $400 \mu \mathrm{M}$ 
dTTP, $2.0 \mathrm{mM} \mathrm{MgCl}$ ), 10 pmol each of GDHeF forward and GDHiR reverse primers, $5 \%$ of dimethyl sulfoxide (DMSO) and nuclease free water (Promega, USA). For the primary reaction, 1.0 to $2.5 \mu \mathrm{l}$ of genomic DNA was added as the template. One microlitre of PCR product from the primary reaction was added to the secondary PCR, which contained GDHiF and GDHiR primers. The secondary PCR reaction mixture consisted of the same reagents in the same quantities as described for the primary reaction mixture with one exception: no DMSO was added. PCR and semi-nested PCR was carried out on an Eppendorf Mastercycle thermocycler (MWG Biotech, Germany) with the following amplification conditions: 1 cycle of $94^{\circ} \mathrm{C}$ for $5 \mathrm{~min}$, followed by 55 cycles of $94^{\circ} \mathrm{C}$ for $30 \mathrm{~s}, 54^{\circ} \mathrm{C}$ for $20 \mathrm{~s}$ and $72^{\circ} \mathrm{C}$ for $45 \mathrm{~s}$. A final extension step of $72^{\circ} \mathrm{C}$ for $7 \mathrm{~min}$ was performed and completed reactions were held at $22^{\circ} \mathrm{C}$.

\section{Electrophoresis and purification of the PCR products}

PCR products were separated by electrophoresis with $1.5 \%$ $(\mathrm{w} / \mathrm{v})$ agarose gels (Promega, USA) in TAE buffer (40 mM Tris$\mathrm{HCl} ; 20 \mathrm{mM}$ acetate; $2 \mathrm{mM}$ EDTA; $\mathrm{pH}$ 7.0) and were stained with SybrSafe ${ }^{\circledR}$ (Invitrogen, USA) DNA gel stain $(1 \mu 1 / 10 \mathrm{ml})$. A 100-bp ladder (Fermentas, USA) and positive and negative controls were included in each gel. Gel images were visualized under UV light and were captured with a gel documentation system (AlphaImager, AlphaEasy FC, AlphaInotech Corporation $\left.{ }^{\circledR}\right)$. PCR products were purified using a Wizard ${ }^{\circledR}$ SV Gel and PCR Clean-up System (Promega, USA) according to the manufacturer's recommended protocol. The purified DNA was stored at $-20^{\circ} \mathrm{C}$ until it was used for sequencing analysis.

\section{RFLP of the GDH gene}

All PCR positive specimens were subjected to restriction fragment length polymorphism (RFLP) analysis. Giardia duodenalis genotypes were determined by RFLP analysis as previously described (Read et al. 2004). Restriction digests were performed directly on PCR products in $20 \mu \mathrm{l}$ reactions. Ten microlitres of PCR product were added to $1 \times$ reaction buffer and 2U Nla IV (New England Biolabs, USA). Digestion took place at $37^{\circ} \mathrm{C}$ for $3 \mathrm{~h}$. Profiles were visualized on $2 \%$ high resolution grade agarose stained with SybrSafe ${ }^{\circledR}$.

\section{Sequencing of Giardia positive samples}

The secondary GDH (432 bp) semi-nested or the SSU-rDNA (292 bp) PCR products of selected samples were sequenced with the BigDye ${ }^{\circledR}$ Terminator v3.1 Cycle Sequencing kit (Applied Biosystems, USA). Sequencing reactions were performed on an ABI 3500 Genetic Analyzer ${ }^{\circledR}$ (Applied Biosystems, USA). The quality of the generated electropherograms was analyzed with ABI software Sequencing Analysis ${ }^{\circledR}$ v5.3. The nucleotide sequences were analyzed using MEGA version 4.0. The resulting sequences were compared with sequences in the GenBank database using BLAST analysis (http://www.ncbi.nlm.nih.gov/ blast).

\section{Data analysis}

Prevalence rate of $G$. duodenalis throughout the study was calculated as the number of infected individuals divided by the number of individual's sampled $\times 100$. Agreements between diagnostic methods were compared using the Kappa test.

The presence or absence of diarrhoea in the study population with or without $G$. duodenalis infection and the prevalence in age groups were compared using the chi-square test $(95 \%$ confidence interval). Diarrhoea was defined as semi-liquid or liquid stool sample. Farm occurrence was calculated as the number of farms with at least one positive sample when compared with the total number of farms in the study. Analysis of chi-square test were made using software GraphPad InStat ${ }^{\circledR}$ version 3.10.

\section{Nucleotide sequence accession numbers}

The SSU-rDNA and GDH genotype AI nucleotide sequences were deposited in the GenBank database under accession no. JF957619 and JF957621, respectively. The SSU-rDNA sequence (isolate BRAcalf20, genotype E) was deposited under accession no. JF957620. The remaining genotype E GDH nucleotide sequences were deposited in the GenBank database under accession nos. JN160733 to JN160739.

\section{RESULTS}

A total of 200 faecal specimens were collected from dairy cattle from Pardinho, Botucatu and Itatinga counties. These samples were examined by three different diagnostic assays. The prevalence of Giardia duodenalis for all animals sampled was 7.5\% (15/200). Faeces were first examined for cysts by a conventional flotation method using zinc sulfate solution. Conventional microscopy analysis of faecal specimens revealed that $G$. duodenalis cysts were detected in six out of all faecal specimens collected (3\%). Enzyme immunoassay (EIA) identified the same six samples that were positive with the conventional morphological technique. Among the 200 cattle samples tested, $15(7.5 \%)$ produced positive PCR signals (GDH and SSU-rDNA genes). No samples that were negative in the PCR assay were positive using microscopy and ELISA. Agreement between diagnostic tests was moderate $($ Kappa $=0.552)$.

All specimens gave the expected length of the bovine mitochondrial PCR product and these data indicate that PCR inhibitors were not responsible for negatives results.

The protozoan was detected on $80 \%(8 / 10)$ of the farms visited. The prevalence of $G$. duodenalis infection varied across farms, with the lowest (5\%) on PAR-1, BTU-5, ITA-9 and ITA-10 and the highest prevalence (20\%) on PAR-2. Positive G. duodenalis samples for each county and farm are shown in Table 1.

\section{Prevalence related to age}

In this study, infection with $G$. duodenalis was more prevalent in younger animals than in older ones $(\mathrm{P}=0.0013)$. Prevalence observed in calves $(14 \%)$ was higher than in cows (1\%). The prevalence related to the age of calves was approximately $30 \%$ for calves at $61-$ 90 days of age and $\sim 17 \%$ for calves at $0-30$ days of age (Fig. 1). However, the point prevalence of $G$. duodenalis appears not to vary within calves age groups $(\mathrm{p}=0.0634)$.

\section{Presence of diarrhoea in calves}

Diarrhoea was recorded in $17 \%(17 / 100)$ of the calves at the time of the sampling. Giardia duodenalis was detected in $17.6 \%(3 / 17)$ of diarrhoeic calves and in $13.2 \%$ $(11 / 83)$ of non-diarrhoeic calves. The percentage did not differ significantly; thus, it was not found to be statistically associated with infection $(\mathrm{P}=0.927)$. 


\section{Genetic characterisation}

All G. duodenalis positive isolates could be typed by RFLP and/or sequencing analysis. Two different restriction patterns from the NlaIV digestion of semi-nested PCR products were obtained. Two genotypes were identified: genotype E (14 samples) and genotype A (one sample). Across all farms, 93\% (14/15) of the G. duodenalis positive animals were infected with genotype E, whereas $7 \%(1 / 15)$ were infected with genotype A. Genotype E was found on all Giardia positive farms sampled. Genotype A was found on a farm in Pardinho in a 4 month-old calf.

Selected isolates in the study were submitted to sequencing analysis, which confirmed our RFLP-genotyping results. The BRAcalf14 (accession no. JF957619) isolate SSUr-DNA sequence exhibited $100 \%$ match with the genotype A isolate from a dairy calf in the USA (GenBank accession no. AY655700; Trout et al. 2004). The other isolate sequenced, BRAcalf20 (accession no. JF957620) exhibited the A-G transition at nucleotide position 92, indicative of the livestock genotype. Its sequence was identical to the previously established genotype E (GenBank accession no. AY655701; Trout et al. 2004).

The GDH PCR positive faecal sample of genotype AI (BRAcalf14, GenBank accession no. JF957621) from the current study had $100 \%$ similarity with a positive G. duodenalis genotype AI isolate (GenBank accession no. EF507642) from cattle in São Paulo from another study (Souza et al. 2007).

A double peak T/C (two overlapping nucleotides) occurred in the electropherograms of three nucleotides sequences at the GDH locus: isolates BRAcalf12 (GenBank accession number JN160733), BRAcalf53 (GenBank accession number JN160735) and BRAcalf84 (GenBank accession number JN160738). This feature is similar to that detected in the isolate ad-133 (GenBank accession number AY178740) at the same position.

\section{DISCUSSION}

The occurrence of Giardia duodenalis infections in cattle was described in several geographic regions. Studies in Canada (Olson et al. 1997, Appelbee et al. 2003, Ralston et al. 2003, Coklin et al. 2007), Australia (O'Handley et al. 2000, Becher at al. 2004), Belgium (Geurden et al. 2004), New Zealand (Hunt et al. 2000), the United States (Trout et al. 2004, 2005, 2006, 2007), Italy (Berrili et al., 2004), Denmark (Langkjaer et al. 2007), the Netherlands (Huetink et al. 2001) and Portugal (Mendonça et al. 2007) have identified animals infected with this parasite.

The prevalence of $G$. duodenalis infection in cattle varies markedly. While many point prevalence studies (only one sample collected from each animal) of cattle report a significant percentage of Giardia-infected animals, cumulative prevalence studies (more than one sample collected of each animal) often observe close to $100 \%$ infec-

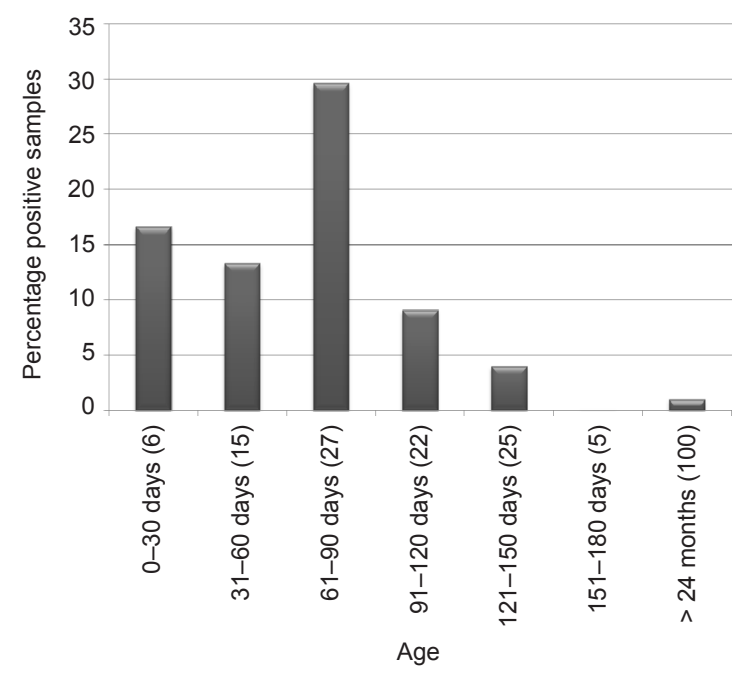

Fig. 1. Age related prevalence (percentage rate) of G. duodenalis in dairy cattle as determined by microscopic examination, ELISA and PCR. Data was averaged across 10 farms in southcentral São Paulo state, Brazil. Numbers in parentheses display the quantity of animals in each category.

tion rates (Xiao and Herd 1994, O'Handley et al. 1999, Ralston et al. 2003, Santín et al. 2009).

In previous studies, the average prevalence of $G$. duodenalis in dairy cattle after faecal examination ranged from 22 to $60 \%$ (O'Handley et al. 2000, Appelbee et al. 2003, Trout el at. 2004, 2005, 2006, 2007, Coklin et al. 2007, Geurden et al. 2008). This finding is higher than the average prevalence $(7.5 \%)$ reported in the current study, but point prevalence data are expected to underestimate the actual prevalence because they are influenced by a range of factors including method and study design, geographical differences, age composition of sampled calves, number of samples from each farm, total number of samples, herd size and sampling season (Hamnes et al. 2006).

As observed by Ralston et al. (2003) and others (Appelbee et al. 2003, Geurden et al. 2004, Trout et al. 2007, Santín et al. 2009), cyst excretion can be intermittent. It is likely that the point prevalence data presented herein underestimates the actual numbers of infected animals on a given farm because only a single faecal sample from each animal was collected.

In the present study, G. duodenalis was detected on $80 \%(8 / 10)$ of the farms sampled, with prevalence ranging from 0 to $20 \%$ in the farms. In four widespread geographic studies in 28 states in the United States, G. duodenalis was present in $100 \%$ of farms with the prevalence in faecal samples analyzed by PCR ranging from 3\% to $93 \%$ in each herd (Trout et al. 2004, 2005, 2006, 2007).

\section{Presence of diarrhoea}

Infection rates were very similar in the faecal samples of non-diarrhoeic (13.2\%) and diarrhoeic (17.6\%) calves. 
As in others studies (Hunt et al. 2000), no relationship was observed between the presence of Giardia cysts and the consistency of the individual faecal specimen.

\section{Age-related Giardia infection}

As described by Trout et al. (2004), O'Handley et al. (2000), Appelbee et al. (2003) and Becher et al. (2004), $G$. duodenalis infections have been frequently reported in pre-weaned calves (under 2 months of age). However, post-weaned calves ( 3 to 11 month-old), heifers (12 to 24 months) and adult cows ( $>24$ months) have also been repeatedly observed as hosts for this parasite (Trout et al. 2005, 2006, 2007, Hamnes et al. 2006, Castro-Hermida et al. 2007).

In our study, the prevalence reached $17 \%$ in 0 to 30 day-old calves, approached $14 \%$ in 30 to 60 day-old calves, and was around $29 \%$ in 61 to 90 day-old calves. The total number of 0 to 2 month-old calves was 21 and prevalence of Giardia in this subgroup was $14 \%(3 / 21)$. In 3 to 6 month-old calves, a total of $14 \%(11 / 79)$ specimens were positive. No significant difference was observed. In a North American study, G. duodenalis cysts were rare in cows and the highest occurrence was found in animals at 4 to 5 weeks old (Santín et al. 2009). On the other hand, Huetink et al. (2001) in the Nerthelands reported that calves 4 to 5 months of age were the most frequently infected age group. Similar to previous studies (O'Handley et al. 1999, Trout et al. 2005, Hamnes et al. 2006), we observed that $30 \%$ of sampled calves at 3 month-old were infected. In pre-weaned, post-weaned, and adult dairy cows on 14 dairy farms in seven eastern states in the United States, Giardia was detected in $40 \%$, $52 \%$, and $27 \%$ of the animals, respectively (Trout et al. 2004, 2005, 2007).

Our results conform to those of previous studies that concluded that giardiasis in calves was generally established during the first months of life and increased when animals were exposed to cysts in the environment (Huetink et al. 2001). Prevalence significantly decreased in adult cows. Infection with $G$. duodenalis in adult animals was only $1 \%(1 / 100)$. A lower prevalence was found in adult dairy cattle compared with young calves, which was also consistent with previous reports (O'Handley et al. 1999, 2000, Appelbee et al. 2003, Mendonça et al. 2007). A high prevalence of $G$. duodenalis was observed by Castro-Hermida et al. (2007) and Trout et al. (2007) in adult dairy cattle.

\section{Genotypes}

Cattle are susceptible to infection by three major genotypes of $G$. duodenalis: the zoonotic genotypes (A and B) and the host-related, non-zoonotic genotype E (Thompson et al. 2000, Monis and Thompson 2003). Similar to our study, genotype $\mathrm{E}$ is most prevalent in dairy cattle from Australia, the United States, Canada and New Zealand and has a wide distribution among cattle farms (Appelbee et al. 2003, Becher et al. 2004, Trout et al. 2004, 2005, 2006, 2007). Others studies revealed various prevalence rates of genotype A in dairy cattle (O'Handley et al. 2000, Uehlinger et al. 2006, Langkjaer et al. 2007).

In a North American molecular epidemiologic study in pre-weaned and post-weaned calves and adult dairy cattle, G. duodenalis genotype A was detected at varying levels on 14 farms studied (Trout et al. 2004, 2005, 2006, 2007). This potentially zoonotic genotype represented $15 \%$ to $25 \%$ of the total Giardia detected in these farms. In the present study, zoonotic genotype AI was detected on only one farm and in approximately $6.6 \%$ of the positive animals (1/15). The current study revealed that dairy cattle on the visited farms had a high occurrence of $G$. duodenalis genotype $\mathrm{E}$, but the zoonotic genotype $\mathrm{A}$ was also reported.

\section{Zoonotic significance}

Cattle have been proposed as a potential source of human Giardia infections through direct contact or contamination of surface water supplies (O'Handley et al. 2000, Thompson et al. 2000, Thompson 2000, Hunter and Thompson 2005). Recent studies have shown high levels of the potentially zoonotic $G$. duodenalis genotype A in dairy cattle (Uehlinger et al. 2006, Geurden et al. 2008). In those studies, the majority of the dairy calves were infected with $G$. duodenalis genotype A. The results of this study confirm that dairy cattle in Brazil can shed Giardia cysts potentially infectious to humans. Further studies in other endemic regions in Brazil are required to fully evaluate the prevalence of zoonotic genotypes and the public health impact of infections with Giardia in dairy cattle.

Acknowledgements. This study was supported by the Fundação de Amparo a Pesquisa do Estado de São Paulo (FAPESP) - grant number 05/52175-2.

\section{REFERENCES}

Appelbee A.J., Frederick L.M., Heitman T.L., Olson M.E. 2003: Prevalence and genotyping of Giardia duodenalis from beef calves in Alberta, Canada. Vet. Parasitol. 112: 289-294.

Barwick R.S., Mohammed H.O., White M.E., Bryant R.B. 2003: Prevalence of Giardia spp. and Cryptosporidium spp. on dairy farms in southeastern New York State. Prev. Vet. Med. 59: 1-11.
Becher K.A., Robertson I.D., Fraser D.M., Palmer D.G., Thompson R.C.A. 2004: Molecular epidemiology of Giardia and Cryptosporidium infections in dairy calves originating from three sources in Western Australia. Vet. Parasitol. 123: $1-9$.

Berrilli F., Di Cave D., De Liberato C., Franco A., Scaramozzino P., Orecchia P. 2004: Genotype characterization of 
Giardia duodenalis isolates from domestic and farm animals by SSU-rRNA gene sequencing. Vet. Parasitol. 122: 193-199.

Castro-Hermida J.A., Almeida A., González-Warleta M., Correia da Costa J.M., Rumbo-Lorenzo C., Mezo M. 2007: Occurrence of Cryptosporidium parvum and Giardia duodenalis in healthy adult domestic ruminants. Parasitol. Res. 101: 1443-1448.

Coklin T., Farber J., Parrington L., Dixon B. 2007: Prevalence and molecular characterization of Giardia duodenalis and Cryptosporidium spp. in dairy cattle in Ontario, Canada. Vet. Parasitol. 150: 297-305.

Faust E.C., D’Antonio J.S., Odom V., Miller M.J., Peres C., Sawitz W., Thomen L.F., Tobie J., Walker J.H. 1938: A critical study of clinical laboratory techniques for the diagnosis of protozoan cysts and helminth eggs in feces. Am. J. Trop. Med. Hyg. 18: 169-183.

Geurden T., Claerebout E., Vercruysse J., Berkvens D. 2004 : Estimation of diagnostic test characteristics and prevalence of Giardia duodenalis in dairy calves in Belgium using a Bayesian approach. Int. J. Parasitol. 34: 1121-1127.

Geurden T., Geldhof P., Levecke B., Martens C., Berkvens D., Casaert S., Vercruysse J., Claerebout E. 2008: Mixed Giardia duodenalis genotype A and $\mathrm{E}$ infections in calves. Int. J. Parasitol. 38: 259-264.

Hamnes I.S., Gjerde B., Robertson L. 2006: Prevalence of Giardia and Cryptosporidium in dairy calves in three areas of Norway. Vet. Parasitol. 140: 204-216.

Hopkins R.M., Meloni B.P., Groth D.M., Wetherall J.D., Reynoldson J.D., Thompson R.C.A. 1997: Ribosomal RNA sequencing reveals differences between the genotypes of Giardia isolates recovered from humans and dogs living in the same locality. J. Parasitol. 83: 44-51.

Huetink R.E.C., van der Giessen J.W.B., Noordhuizen J.P.T.M., Ploeger H.W. 2001: Epidemiology of Cryptosporidium spp. and Giardia duodenalis on a dairy farm. Vet. Parasitol. 102: 53-67.

Hunt C.L., Ionas G., Brown T.J. 2000: Prevalence and strain differentiation of Giardia intestinalis in calves in the Manawatu and Waikato regions of North Island, New Zealand. Vet. Parasitol. 91: 7-13.

Hunter P.R., Thompson R.C.A. 2005: The zoonotic transmission of Giardia and Cryptosporidium. Int. J. Parasitol. 35: 1181-1190.

LangkJaer R.B., Vigre H., Enemark H.L., Maddox-Hyttel C. 2007: Molecular and phylogenetic characterization of Cryptosporidium and Giardia from pigs and cattle in Denmark. Parasitology 134: 339-350.

Leonhard S., Pfister K., Beelitz P., Wielinga C., Thompson R.C.A. 2007: The molecular characterization of Giardia from dogs in southern Germany. Vet. Parasitol. 150: 33-38.

Martellini A., Payment P., Villemur R. 2005: Use of eukaryotic mitochondrial DNA to differentiate human, bovine, porcine and ovine sources in faecally contaminated surface water. Water Res. 39: 541-548.

Mendonça C., Almeida A., Castro A., de Lurdes Delgado M., Soares S., da costa J.M., Canada N. 2007: Molecular characterization of Cryptosporidium and Giardia isolates from cattle from Portugal. Vet. Parasitol. 147: 47-50.

Monis P.T., Andrews R.H., Mayrhofer G., Ey P.L. 2003: Genetic diversity within the morphological species Giardia intestinalis and its relationship to host origin. Infect. Genet. Evol. 3: $29-38$.

Monis P.T., Thompson R.C.A. 2003: Cryptosporidium and Giardia zoonoses: fact or fiction? Infect. Genet. Evol. 3: 233-244.
O’Handley R.M., Cockwill C., McAllister T.A., Jelinski M., Morck D.W., Olson M.E. 1999: Duration of naturally acquired giardiasis and cryptosporidiosis in dairy calves and their association with diarrhea. J. Am. Vet. Med. Assoc. 214: 391-396.

O’Handley R.M., Olson M.E., Fraser D., Adams P., ThompSON R.C.A. 2000: Prevalence and genotypic characterization of Giardia in dairy calves from Western Australia and Western Canada. Vet. Parasitol. 90: 193-200.

Olson M.E., McAllister T.A., Deselliers L., Morck D.W., Cheng K.J., Buret A.G., Ceri H. 1995: Effects of giardiasis on production in a domestic ruminant (lamb) model. Am. J. Vet. Res. 56: 1470-1474.

Olson M.E., Thorlakson C.L., Deselliers L., Morck D.W., McAllister T.A. 1997: Giardia and Cryptosporidium in Canadian farm animals. Vet. Parasitol. 68: 375-381.

Olson M.E., Thorlakson C.L., Deselliers L., Morck D.W., McAllister T.A. 2004: Update on Cryptosporidium and Giardia infections in cattle. Trends Parasitol. 20: 185-191.

Ralston B.J., McAllister T.A., Olson M.E. 2003: Prevalence and infection pattern of naturally acquired giardiasis and cryptosporidiosis in range beef calves and their dams. Vet. Parasitol. 114: 113-122.

Read C.M., Monis P.T., Thompson R.C.A. 2004: Discrimination of all genotypes of Giardia duodenalis at the glutamate dehydrogenase locus using PCR-RFLP. Infect. Genet. Evol. 4: 125-130.

Santín M., Trout J.M., FAyer R. 2009: A longitudinal study of Giardia duodenalis genotypes in dairy cows from birth to 2 years of age. Vet. Parasitol. 16: 240-245.

Souza S.L., Gennari S.M., Richtzenhain L.J., Pena H.F., Funada M.R., Cortez A., Gregori F., Soares R.M. 2007: Molecular identification of Giardia duodenalis isolates from humans, dogs, cats and cattle from the state of São Paulo, Brazil, by sequence analysis of fragments of glutamate dehydrogenase (gdh) coding gene. Vet. Parasitol. 149: 258-264.

THOMpson R.C.A. 2000: Giardiasis as a re-emerging infectious disease and its zoonotic potential. Int. J. Parasitol. 30: 12591267.

Thompson R.C.A. 2004: The zoonotic significance and molecular epidemiology of Giardia and giardiasis. Vet. Parasitol. 126: $15-35$.

Thompson R.C.A., Hopkins R.A., Homan W.L. 2000: Nomenclature and genetic groupings of Giardia infecting mammals. Parasitol. Today 16: 210-218.

Trout J.M., Santín M., Greiner E., Fayer R. 2004: Prevalence of Giardia duodenalis genotypes in pre-weaned dairy calves. Vet. Parasitol. 124: 179-186.

Trout J.M., Santín M., Greiner E., Fayer R. 2005: Prevalence and genotypes of Giardia duodenalis in post-weaned dairy calves. Vet. Parasitol. 130: 177-183.

Trout J.M., Santín M., Greiner E., Fayer R. 2006: Prevalence and genotypes of Giardia duodenalis in 1-2 year old dairy cattle. Vet. Parasitol. 140: 217-222.

Trout J.M., Santín M., Greiner E., Fayer R. 2007: Prevalence and genotypes of Giardia duodenalis in adult dairy cows. Vet. Parasitol. 147: 205-209.

Uehlinger F.D., Barkema H.W., Dixon B.R., Coklin T., O'Handey R.M. 2006: Giardia duodenalis and Cryptosporidium spp. in a veterinary college bovine teaching herd. Vet. Parasitol. 142: 231-237.

Xiao L., Herd R.P. 1994: Infection pattern of Cryptosporidium and Giardia in calves. Vet. Parasitol. 55: 257-262. 